\title{
166. The Control of Growth and Development in Bombyx mori. XVIII
}

\author{
Production of Non-Diapause Eggs by Injection \\ of the Juvenile Hormone
}

\author{
By Seijiro Morohoshi, Sadayoshi IshIDA, and Hajime Fugo \\ Faculty of Agriculture, Tokyo University of Agriculture and Technology, \\ Fuchu-shi, Tokyo 183
}

(Comm. by Hitoshi Kinara, M. J. A., Dec. 12, 1972)

It has been demonstrated in the silkworm that the brain-suboesophageal ganglion system acts a diapause direction and the braincorpora allata system acts a non-diapause or a diapause direction. The suboesophageal ganglion hormone accelerates the accumulation of glycogen and lipid into pupal ovaries, and the corpus allatum hormone is related to protein, lipid and carbohydrate metabolisms in larval and pupal development .

The identification and synthesis of the juvenile hormone $(\mathrm{JH})$ in insects (Röller et al., 1967; Dahm et al., 1967; Chang et al., 1971) have prompted our studies in this area. We succeeded in production of non-diapause eggs by injecting the JH into the 5th instar larvae, but we could not succeed in injections during pupal stage.

Materials and methods. The race used was a bivoltine hybrid between Japanese No. 106 and Daizo. Eggs of this race were incubated at low temperature $\left(17^{\circ} \mathrm{C}\right)$ in the dark $(\mathrm{LD})$ or at high temperature $\left(25^{\circ} \mathrm{C}\right)$ in the light $(\mathrm{HL})$. The former produced only nondiapause egg batches and the latter only diapause egg batches.

In larval experiments, $1 \gamma$ and $10 \gamma \mathrm{JH}$ dissolved in olive oil or $1 \gamma$ ecdysterone $(\mathrm{Ec})$ dissolved in distilled water were injected into 30 larvae at each assay every day during the 5th instar. In pupal experiments, JH of $1 \gamma$ to $10 \gamma$ or Ec of $1 \gamma$ to $5 \gamma$ were injected into 30 pupae at each assay every day after pupation. The controls were injections of olive oil for the $\mathrm{JH}$ and injections of distilled water for the Ec. Amounts injected were $0.005 \mathrm{ml}$ of the $\mathrm{JH}$ and $0.02 \mathrm{ml}$ of the Ec per animal in larvae, and were $0.01 \mathrm{ml}$ per animal in both the $\mathrm{JH}$ and the Ec in pupae. The $\mathrm{JH}$ used were two types of methylenedioxyphenyl derivatives (M.D.D. No. 1 and No. 2, see Report XVII of this series).

Total glycogens were measured by the phenol-sulfuric acid method (Good et al., 1933). Determination of nitrogen content was made by the micro-Kjeldahl method. 
Results. The change of voltinism was observed only in the injection of the M. D. D. No. 1, but not observed in the injection of the M. D. D. No. 2. Accordingly, the results are due to the injection of the M. D. D. No. 1.

I. Effect of the JH on voltinism. a) Injections during 5th larval instar in the HL series. The injection was performed every 24 hours during the 5 th larval instar. The series injected $1 \gamma$ of the $\mathrm{JH}$ showed no difference between experiments and controls as shown in Table I, but all the series injected $10 \gamma$ showed longer larval and pupal duration, more weight in cocoon and cocoon shell, more nondiapause moths as compared with the controls.

Pupal stage of the insects injected $10 \gamma$ prolonged about 1 to 7 days more as compared with the controls or $1 \gamma$ series. Although the insects at the $96 \mathrm{hr}$ old 5 th larvae showed no prolongation of larval and pupal duration, they highly changed in voltinism. It is very interesting that the moths which most prolonged emergence produced non-diapause egg batches, for this phenomenon is the opposite to the normal case. These results were ascertained by repeating experiments 3 times.

Table I. Effect of the $\mathrm{JH}$ on the development of the 5th instar larvae and pupae in the HL series

\begin{tabular}{|c|c|c|c|c|c|c|}
\hline $\begin{array}{c}\text { Stage during } \\
5 \text { th instar } \\
\text { in injection } \\
(\mathrm{hr})\end{array}$ & $\begin{array}{l}\text { Adminis- } \\
\text { tered } \\
\text { dose }(\gamma)\end{array}$ & $\begin{array}{c}\text { Dura- } \\
\text { tion } \\
\text { of } 5 \text { th } \\
\text { instar } \\
(\mathrm{hr})\end{array}$ & $\begin{array}{c}\text { Cocoon } \\
\text { weight }(g)\end{array}$ & $\begin{array}{l}\text { Cocoon } \\
\text { shell } \\
\text { weight } \\
\text { (cg) }\end{array}$ & $\begin{array}{l}\text { Pupal } \\
\text { stage } \\
\text { (day) }\end{array}$ & $\begin{array}{c}\% \text { of non- } \\
\text { diapause } \\
\text { moths* (No.) }\end{array}$ \\
\hline \multirow{3}{*}{0} & Control (oil) & 134.6 & $1.71 \pm 0.18$ & $22.2 \pm 1.9$ & 9.5 & $5.56(1 / 18)$ \\
\hline & $\mathrm{JH} \quad 1 \gamma$ & 145.5 & $1.70 \pm 0.27$ & $22.2 \pm 2.4$ & 10.0 & $4.35(1 / 23)$ \\
\hline & $\mathrm{JH} \quad 10 \gamma$ & 147.3 & $1.90 \pm 0.23$ & $24.8 \pm 2.9$ & 10.9 & $40.91(9 / 22)$ \\
\hline \multirow{3}{*}{24} & Control (oil) & 139.9 & $1.65 \pm 0.13$ & $21.8 \pm 1.8$ & 10.0 & $0.00(0 / 22)$ \\
\hline & $\mathrm{JH} \quad 1 \gamma$ & 140.5 & $1.70 \pm 0.15$ & $21.8 \pm 2.3$ & 10.0 & $4.50(1 / 22)$ \\
\hline & $\mathrm{JH} 10 \gamma$ & 162.8 & $1.89 \pm 0.20$ & $25.3 \pm 2.9$ & 11.2 & $35.00(7 / 22)$ \\
\hline \multirow{3}{*}{48} & Control (oil) & 138.0 & $1.64 \pm 0.12$ & $21.9 \pm 2.0$ & 9.8 & $0.00(0 / 20)$ \\
\hline & $\mathrm{JH} \quad 1 \gamma$ & 148.5 & $1.72 \pm 0.12$ & $22.2 \pm 2.4$ & 10.6 & $0.00(0 / 19)$ \\
\hline & $\mathrm{JH} \quad 10 \gamma$ & 168.1 & $1.93 \pm 0.37$ & $24.5 \pm 3.2$ & 13.3 & $52.38(11 / 21)$ \\
\hline \multirow{3}{*}{72} & Control (oil) & 137.4 & $1.58 \pm 0.11$ & $19.8 \pm 2.1$ & 10.0 & $10.00(2 / 20)$ \\
\hline & $\mathrm{JH} \quad 1 \gamma$ & 137.9 & $1.56 \pm 0.24$ & $19.2 \pm 2.5$ & 10.0 & $9.52(2 / 21)$ \\
\hline & $\mathrm{JH} \quad 10 \gamma$ & 161.9 & $1.93 \pm 0.35$ & $21.5 \pm 3.1$ & 13.5 & $63.63(14 / 22)$ \\
\hline \multirow{3}{*}{96} & Control (oil) & 135.9 & $1.56 \pm 0.13$ & $20.8 \pm 1.9$ & 10.0 & $0.00(0 / 20)$ \\
\hline & $\mathrm{JH} \quad 1 \gamma$ & 135.2 & $1.64 \pm 0.20$ & $21.8 \pm 2.1$ & 10.4 & $11.11(2 / 18)$ \\
\hline & $\mathrm{JH} 10 \gamma$ & 139.3 & $1.70 \pm 0.21$ & $19.4 \pm 2.8$ & 10.5 & $75.00(12 / 16)$ \\
\hline
\end{tabular}

*: Moths laid over 50\% non-diapause eggs out of one batch were calculated as non-diapause moths. 
b) Injections during 5th larval instar in the LD series. The individuals injected $10 \gamma$ of the $\mathrm{JH}$ prolonged emergence like the case in the HL series. However, no change of voltinism was observed in the experimental series like the controls.

c) Injections during pupal stage. The 0, 24, 48, 72, 96 and 120 hr old female pupae were injected $1 \gamma$ or $10 \gamma$ of the juvenile hormone in both the HL and the LD series. The experimental pupae showed no change in both the subsequent pupal duration and voltinism as cmpared with the controls. The effect of the administration of the $\mathrm{JH}$ on voltinism was not observed in pupal stage.

II. Effect of the Ec on voltinism. a) Injections during 5th larval instar in the HL series. Injections in the $\mathrm{O}$ or $24 \mathrm{hr}$ old 5 th instar larvae lengthened the subsequent larval or pupal duration and increased the body weight as compared with the controls. In injections in the 48 or $72 \mathrm{hr}$ old 5th instar larvae, any significant differences were not observed between the experiments and controls concerning the subsequent larval or pupal duartion and the body weight. In injections in the $96 \mathrm{hr}$ old 5 th instar larvae, its larval or pupal duration and the body weight decreased more than the controls. However, any significant difference of voltinism was not observed in all the experiments as compared with the controls, as shown in Table II.

b) Injections during 5th larval instar in the LD series. The effect of the Ec on the larval development during the 5th instar was similar to the case in the HL series. The change of voltinism by

Table II. Effect of Ecdysterone on the development of the 5th instar larvae and pupae in the HL series

\begin{tabular}{|c|c|c|c|c|c|c|}
\hline $\begin{array}{c}\text { Stage during } \\
5 \text { th instar } \\
\text { in injection } \\
(\mathrm{hr})\end{array}$ & $\begin{array}{l}\text { Adminis- } \\
\text { tered } \\
\text { dose }(\gamma)\end{array}$ & $\begin{array}{c}\text { Dura- } \\
\text { tion } \\
\text { of } 5 \text { th } \\
\text { instar } \\
\text { (hr) }\end{array}$ & $\begin{array}{c}\text { Cocoon } \\
\text { weight }(\mathrm{g})\end{array}$ & $\begin{array}{l}\text { Cocoon } \\
\text { shell } \\
\text { weight } \\
\text { (cg) }\end{array}$ & $\begin{array}{l}\text { Pupal } \\
\text { stage } \\
\text { (day) }\end{array}$ & $\begin{array}{l}\% \text { of non- } \\
\text { diapause } \\
\text { moths (No.) }\end{array}$ \\
\hline \multirow{2}{*}{0} & Control (dw) & 139.4 & $1.76 \pm 0.14$ & $23.7 \pm 2.0$ & 9.8 & $6.25(1 / 16)$ \\
\hline & Ec $1 r$ & 185.0 & $1.85 \pm 0.20$ & $26.2 \pm 2.9$ & 14.8 & $0.00(0 / 22)$ \\
\hline \multirow{2}{*}{24} & Control (dw) & 140.1 & $1.70 \pm 0.13$ & $22.6 \pm 1.9$ & 9.9 & $0.00(0 / 20)$ \\
\hline & Ec $1 \gamma$ & 155.9 & $1.81 \pm 0.25$ & $26.0 \pm 2.8$ & 13.2 & $5.26(1 / 10)$ \\
\hline \multirow{2}{*}{48} & Control (dw) & 140.4 & $1.64 \pm 0.14$ & $21.7 \pm 1.8$ & 10.1 & $0.00(0 / 21)$ \\
\hline & Ec $1 \gamma$ & 143.0 & $1.66 \pm 0.15$ & $22.2 \pm 2.1$ & 10.1 & $4.86(1 / 21)$ \\
\hline \multirow{2}{*}{72} & Control (dw) & 141.0 & $1.59 \pm 0.16$ & $20.0 \pm 1.9$ & 10.1 & $7.14(1 / 14)$ \\
\hline & $\operatorname{Ec} 1 \gamma$ & 134.5 & $1.53 \pm 0.17$ & $19.3 \pm 1.8$ & 9.6 & $9.09(2 / 22)$ \\
\hline \multirow{2}{*}{96} & Control (dw) & 134.3 & $1.58 \pm 0.14$ & $19.2 \pm 2.0$ & 9.7 & $11.11(2 / 18)$ \\
\hline & Ec $1 \gamma$ & 126.3 & $1.45 \pm 0.13$ & $17.8 \pm 1.8$ & 9.1 & $0.00(0 / 22)$ \\
\hline
\end{tabular}


injection of $1 \gamma$ Ec was not observed.

c) Injections during pupal stage. The $48 \mathrm{hr}$ old female pupae were injected $1 \gamma, 3 \gamma$ and $5 \gamma$ of the Ec in both the HL and the LD series. The pupae injected showed no difference in both the subsequent pupal duration and voltinim as compared with the controls.

III. Effect of the JH injected in the 3 days old 5th instar larvae on amounts of glycogen and nitrogen of pupal fat body and ovary. We succeeded in production of non-diapause egg batches by injection of the $\mathrm{JH}$ into the 5th instar larvae (HL). Why did the change of voltinism occur? Amounts of nitrogen and glycogen in the fat body and ovary of the pupae which developed from the insects into which the $\mathrm{JH}$ was injected in the 3 days old 5th instar larvae were examined. The component content of the ovary in the $5 \gamma$ or $10 \gamma \mathrm{JH}$ injection was, as shown in Fig. 1, less in nitrogen (N) and less in
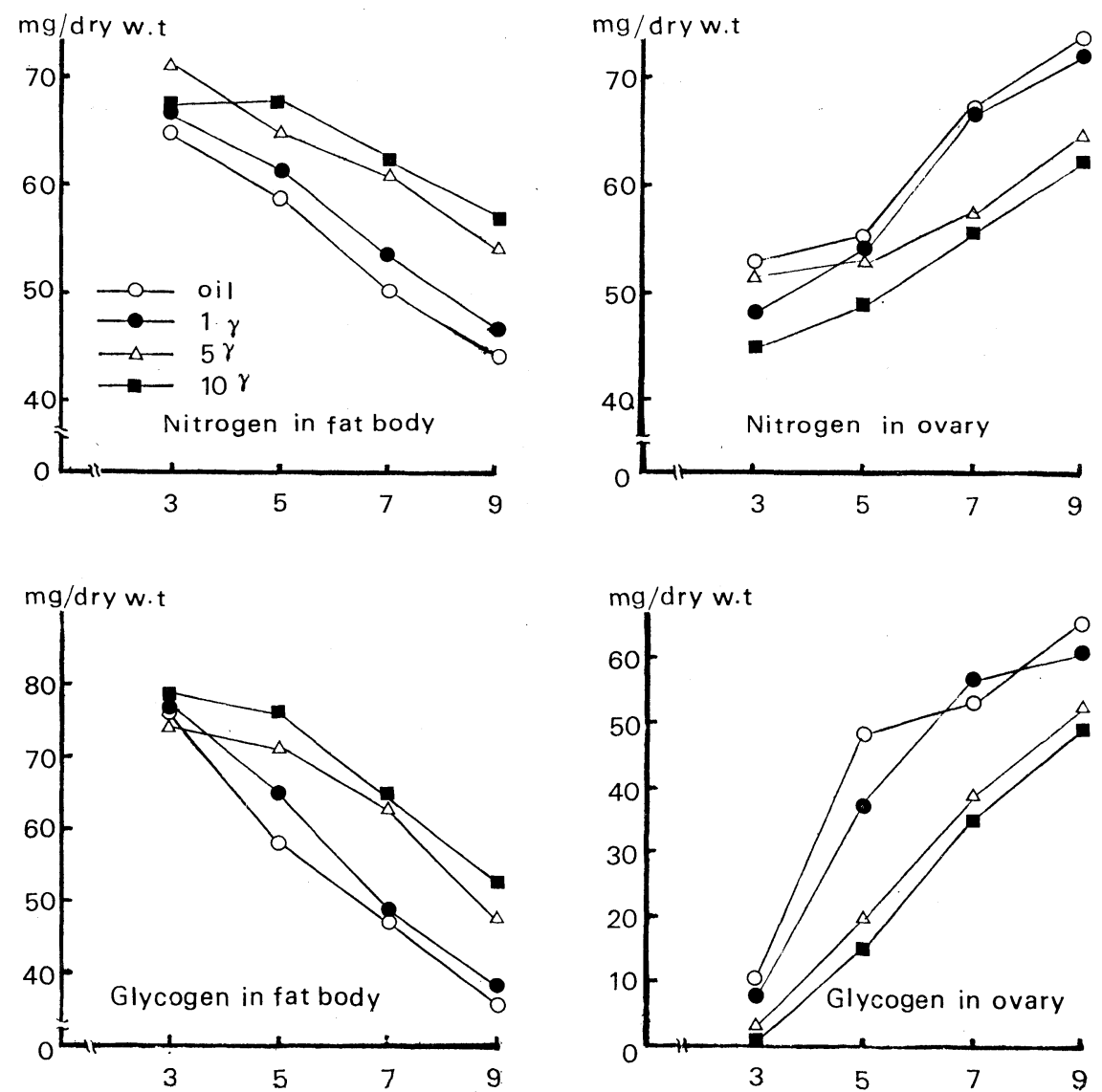

Fig. 1. Effect of the JH injected in the 3 days old 5th instar larvae on amounts of nitrogen and glycogen of pupal fat body and ovary. Ordinate: $\mathrm{mg} / \mathrm{g}$ dry weight, Abscissa: pupal age in days. 
glycogen (C) as compared with the controls or $1 \gamma$ injection. But the component content of the ovary of the $5 \gamma$ or $10 \gamma \mathrm{JH}$ injection showed a lower ratio of $\mathrm{C} / \mathrm{N}$ like non-diapause eggs.

Main component content of diapause eggs is more in glycogen and lipid, and less in nitrogen as compared with that of non-diapause eggs. A component of glycogen gradually decreased as the days went by in both diapause and non-diapause eggs as shown in Table III. The decrease of glycogen may be due to the convertion of the glycogen into sorbitol and glycerol during diapause (Chino, 1959) and also due to the utilization for the embryonic development in non-diapause eggs. A component of lipid did not change as the days went by in diapause eggs, but it gradually decreased in non-diapause or artificially hatching eggs. A component of nitrogen gradually increased as the days went by in both diapause and non-diapause eggs, and especially extremely in non-diapause eggs.

Table III. Chemical analysis in diapause and non-diapause eggs

\begin{tabular}{|c|c|c|c|c|}
\hline \multirow{2}{*}{ Voltinism } & \multirow{2}{*}{$\begin{array}{l}\text { Days after } \\
\text { oviposition }\end{array}$} & \multicolumn{3}{|c|}{ mg/g egg wet weight } \\
\hline & & Glycogen & Lipid & Nitrogen \\
\hline \multirow{6}{*}{ Diapause eggs } & 0 & $41.5 \pm 0.3$ & $109.6 \pm 0.3$ & $120.3 \pm 0.3$ \\
\hline & 1 & $39.5 \pm 0.4$ & $109.0 \pm 0.6$ & $127.5 \pm 0.8$ \\
\hline & 2 & $21.7 \pm 0.4$ & $106.4 \pm 0.9$ & $131.5 \pm 0.2$ \\
\hline & 3 & $19.2 \pm 0.8$ & $109.6 \pm 0.3$ & $133.7 \pm 0.7$ \\
\hline & 4 & $15.3 \pm 0.3$ & $108.9 \pm 0.5$ & $134.4 \pm 0.5$ \\
\hline & 5 & $12.7 \pm 0.3$ & $109.0 \pm 0.8$ & $135.3 \pm 0.7$ \\
\hline \multirow{10}{*}{ Non-diapause eggs } & 0 & $35.2 \pm 0.3$ & $88.7 \pm 0.4$ & $128.9 \pm 0.4$ \\
\hline & 1 & $36.7 \pm 0.7$ & $86.5 \pm 0.5$ & $130.8 \pm 0.4$ \\
\hline & 2 & $34.0 \pm 0.5$ & $77.2 \pm 0.3$ & $135.2 \pm 0.8$ \\
\hline & 3 & $29.3 \pm 0.8$ & $73.6 \pm 0.7$ & $142.5 \pm 0.2$ \\
\hline & 4 & $30.6 \pm 0.3$ & $73.7 \pm 0.3$ & $156.6 \pm 0.3$ \\
\hline & 5 & $26.4 \pm 0.4$ & $61.7 \pm 0.2$ & $151.4 \pm 0.7$ \\
\hline & 6 & $24.5 \pm 0.7$ & $57.6 \pm 0.3$ & $166.5 \pm 0.5$ \\
\hline & 7 & $20.7 \pm 0.3$ & $54.3 \pm 0.6$ & $166.8 \pm 0.6$ \\
\hline & 8 & $21.3 \pm 0.4$ & $43.2 \pm 0.7$ & $166.9 \pm 0.4$ \\
\hline & 9 (hatch) & $17.7 \pm 0.3$ & $41.6 \pm 0.3$ & $165.3 \pm 0.7$ \\
\hline \multirow{6}{*}{$\begin{array}{l}\text { Diapause eggs } \\
\text { artificially treated } \\
\text { with HCl } 20 \text { hours } \\
\text { after oviposition }\end{array}$} & $10^{*}$ & $17.8 \pm 0.3$ & $128.0 \pm 0.3$ & $127.1 \pm 0.2$ \\
\hline & 11 & $23.7 \pm 0.5$ & $122.0 \pm 0.6$ & $127.3 \pm 0.3$ \\
\hline & 13 & $39.3 \pm 0.3$ & $118.0 \pm 0.5$ & $132.8 \pm 0.8$ \\
\hline & 15 & $28.0 \pm 0.6$ & $112.6 \pm 0.3$ & $142.6 \pm 0.4$ \\
\hline & 17 & $21.7 \pm 0.7$ & $106.3 \pm 0.2$ & $146.6 \pm 0.5$ \\
\hline & 20 (hatch) & $20.1 \pm 0.5$ & $73.1 \pm 0.3$ & $153.7 \pm 0.6$ \\
\hline
\end{tabular}

*: Maintained at $5^{\circ} \mathrm{C}$ for 9 days after hydrochlorizing. 
Discussion. From these results, it seems to be that the diapause phenomenon is observed at more accumulation of glycogen and lipid (C), and its breaking is observed at more accumulation of nitrogen or protein $(\mathrm{N})$ as the following shema:

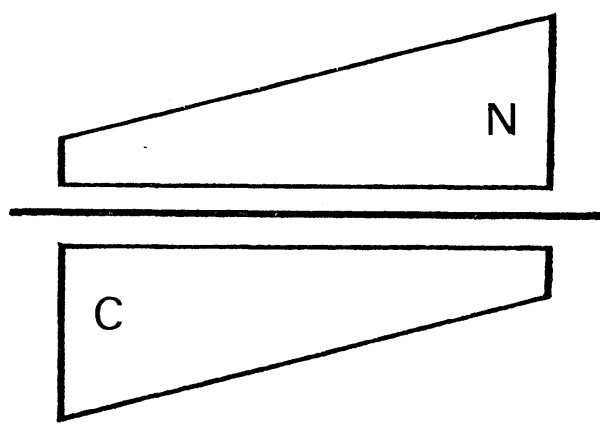

1

2

Fig. 2. $\mathrm{C} / \mathrm{N}$ ratio in the beginning and end during diapause.

1: beginning, 2: end, $\mathrm{N}$ : protein, C: lipid and glycogen.

The voltinism is strictly determined by the activity of the corpora allata (CA) and the suboesophageal ganglion (SG) in the final instar. When its activity is strong in both the CA and the SG, "diapause individuals" are produced and when weak, "non-diapause" (see Report XV of this series). However, when the function of the CA is extremely enhanced by injection of the $\mathrm{JH}$, voltinism changes from diapause to non-diapause direction. This phenomenon is observed only in injection of the $\mathrm{JH}$ into the 5th instar larvae and it is not observed in injection into pupae. The ecdysterone has no effect on the change of voltinism.

Diapausing eggs have a large amount of lipid and glycogen (C), but they have a small amount of protein $(\mathrm{N})$ as compared with that of non-diapausing eggs. The entrance into diapause seems to be mainly controlled by amounts of lipid and glycogen, and the breaking of the diapause seems to be mainly controlled by amounts of protein. It is natural that the $\mathrm{C} / \mathrm{N}$ ratio is related to the maturity of insects.

Acknowledgement. The authors wish to express their thanks to Dr. S. Tamura, Professor of Tokyo University, Tokyo, Japan, for the offering of these valuable juvenile hormones and to Dr. T. Takemoto, Professor of Tohoku University, Sendai, Japan, for the offering of this valuable ecdysterone. This investigation was supported by a grant in aid for fundamental scientific research from the Ministry of Education, Japan. 